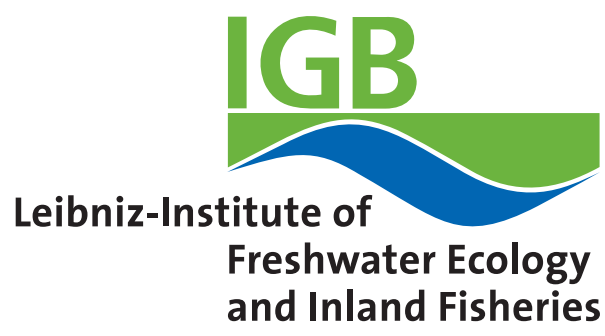

\title{
Sturgeon and paddlefish life history and management: experts' knowledge and beliefs
}

Ivan Jaric (D) https://orcid.org/0000-0002-2185-297X, Carsten Riepe, Jörn Geßner

DOI

https://doi.org/10.1111/jai.13563

Original publication date

15 December 2017 (Version of record online)

Document version

Accepted version

\section{Published in}

Journal of Applied Ichthyology

\section{Citation}

Jaric I, Riepe C, Geßner J. Sturgeon and paddlefish life history and management: experts' knowledge and beliefs. Journal of Applied Ichthyology. 2018;34(2):244-57. 
Sturgeon and paddlefish life history and management: experts' knowledge and beliefs

\footnotetext{
Ivan Jarić $^{1,2^{*}}$, Carsten Riepe ${ }^{1}$ and Jörn Gessner ${ }^{1}$

${ }^{1}$ Leibniz-Institute of Freshwater Ecology and Inland Fisheries, Müggelseedamm 310, 12587 Berlin, Germany

${ }^{2}$ Institute for Multidisciplinary Research, University of Belgrade, Kneza Viseslava 1, 11000 Belgrade, Serbia

* Author to whom correspondence should be addressed: Leibniz-Institute of Freshwater Ecology and Inland Fisheries, Müggelseedamm 310, 12587 Berlin, Germany; E-mail: jaric@igb-berlin.de; phone: +49 (0)30 64181 766, fax.: +49 (0)30 64181626
} 


\section{Summary}

Although sturgeons and paddlefish represent a highly endangered species group, our knowledge regarding their ecology, life history and management and restoration measures still reveals substantial gaps and uncertainties. As such, we hypothesized that the information on the overall experiences and perspectives of the researchers working in the field would provide a good indication on the state of knowledge, and help identify fields for further investigation. To gain in-depth insight into their perspectives on a variety of topics related to sturgeon life history, management and conservation, as well as their opinion on issues characterized by a lack of data, we conducted an online survey among scientists worldwide who have been specializing in sturgeon and paddlefish research. With a total of 277 respondents, the response rate was good (40.3\% of the invited persons). The survey results indicated a high level of uncertainty with regard to various aspects of sturgeon life history, such as spawning migrations, reproduction and senescence. Responses differed largely depending upon the regional background and the research focus of the participants. Agreement with reported extreme dimensions and lifespans in sturgeons varied among species, but the level of agreement in general was higher among those scientists dealing with the species in question. When threats are concerned, responses were regionally specific, with dams and habitat fragmentation recognized as major threats by researchers from North America, while poaching was dominant threat in Europe and Asia. Sturgeon aquaculture was generally considered as having a positive effect on sturgeon protection by reducing the pressure on natural 
populations. Among the conventions, the Convention on International Trade in Endangered Species of Wild Fauna and Flora (CITES) was recognized as the most effective instrument in international sturgeon conservation. While sturgeons are generally perceived as flagship species, especially in Europe, their potential utilization as umbrella species was questioned by the participants. Besides obtaining insight into available scientific information, as well as the general level of consensus regarding some of the questions tackled, the results of the survey also create a basis for further discussion within the scientific community concerning the validity, relevance, and application of published information, and future research priorities.

\section{Introduction}

Due to their susceptibility to habitat degradation and fragmentation, as well as to overfishing, sturgeons and paddlefish (order Acipenseriformes) represent the most endangered group of fish (Jarić and Gessner, 2012). As many as $63 \%$ of the species belonging to this order are classified as Critically Endangered, with three species additionally listed as Possibly Extinct, and further 30\% classified as either Near Threatened, Vulnerable or Endangered (IUCN, 2016). Increased awareness of their deteriorated status (Bemis and Kynard 1997) stimulated increased demand for new information on their biogeography, physiology, life history and evolutionary history (Billard and Lecointre, 2001), which led to a substantial increase of research efforts over time (Jarić and Gessner, 2012). However, the published research focused 
on a few species, regions and topics (Jarić and Gessner, 2012; Gessner et al., 2013). As a result, the gaps in knowledge, especially on their biology, demography and life history are still substantial (Jarić et al., 2009; Pollock et al., 2015). Such lack of knowledge has the potential to adversely affect management efficiency, conservation planning, and enforcement.

The goal of the present study was to gain insight into experiences and perspectives of the scientific community on various topics related to sturgeon and paddlefish life history, management and conservation, as well as their personal opinion on issues characterized by a lack of available data. Besides obtaining insight into available scientific information and the general level of consensus among scientists regarding some of the tackled questions (with regard to lifespan, senescence, maximum dimensions, migration and mating characteristics, anthropogenic impacts, etc.), the results of the survey were also aimed at identifying understudied research topics for further investigation, as well as creating a basis for further discussion within the scientific community.

\section{Material and methods}

The survey instrument was developed and administered in English language and according to standard principles of survey methodology and questionnaire construction (Das et al., 2011; Dillman et al., 2014). It comprised 22 questions with precoded response categories. In addition, each of the questions offered the opportunity for the respondents to supplement their responses with 
individual comments by means of an open-ended response category. Most questions also offered a not sure category to enable respondents to indicate that they were uncertain about their answer (Supplementary material). The first six questions addressed the scientific background of the respondents (i.e., the extent of their research focus on sturgeons and paddlefish, number of years that they had been working in sturgeon research, number of [co]authored publications dealing with these species, species and regions studied, fields of research). The 12 questions that followed addressed aspects of sturgeon and paddlefish life history and ecology: presence and importance of senescence in sturgeons, mating type, homing fidelity and its drivers, maximum lifespans and maximum body weight and length (both through general questions and questions addressing specific species and speciesrelated reports), maximum population growth rates, and the importance of inbreeding and outbreeding depressions in sturgeon populations at low abundances. The last four questions addressed different issues regarding sturgeon and paddlefish management and conservation, including their potential to be used as a surrogate species (i.e., as umbrella, flagship or indicator species), major anthropogenic impacts, the potential of sturgeon aquaculture development to reduce pressure on natural populations, and the effectiveness and impact of different international conventions regarding sustainable management of sturgeon and paddlefish populations. Respondents were asked to evaluate the importance of major anthropogenic impacts on population status (i.e., poaching, bycatch, deteriorated water quality and pollution, poor habitat quality, dam construction and habitat 
fragmentation) by ranking them, while their views on the efficiency of international conventions were elicited by means of a rating scale. The survey was administered electronically using an online survey platform (www.surveymonkey.com).

The survey was conducted worldwide among sturgeon and paddlefish researchers who published at least one article on sturgeons or paddlefish as corresponding persons during the last five years before the survey was conducted. The list of publications dealing with sturgeons and paddlefish were obtained from the ISI Web of Knowledge online database, using the following search queries: "sturgeon* OR paddlefish* OR acipenser* OR huso OR scaphirhynch* OR pseudoscaphirhynchus OR psephurus OR polyodon*”, to search through the titles, abstracts and keywords of referenced publications published since 2011 (Jarić and Gessner, 2012). The search was conducted in February 2016, and the results were limited to articles, review papers and conference proceedings published within the ISI subject categories Fisheries, Marine \& Freshwater Biology, Environmental Sciences \& Ecology, and Biodiversity \& Conservation. The query resulted in a total number of 1,122 publications. After excluding mismatches, email addresses of corresponding authors were obtained from each of the papers, if available.

Following removal of duplicate entries, the email list contained 713 unique addresses. An invitation to participate in the survey was sent out in February 2016, followed by a reminder email one week later. Respondents were informed that their participating in the survey was voluntary but important, and that all data would be processed and published anonymously, but respondents would be provided with the 
access to results if they so indicated in the questionnaire and supplied us with an email address.

Results were assessed within the total sample, as well as per specific groups, such as researchers focusing on different regions, species and research fields. Experienced researchers were defined as persons who had been working regularly or exclusively with sturgeons and paddlefish for more than 10 years. Species experts were defined as researchers working with a given species.

\section{Results and discussion}

The present study represents the first survey of this kind and scope, providing evaluation of experiences and perspectives of the scientific community on different issues related to the ecology, life history and management of sturgeons and paddlefish. The two previous surveys within the community of sturgeon and paddlefish researchers, conducted by Beamesderfer and Farr (1997) and Williot et al. (2002) in North America and Eurasia, respectively, had a much narrower scope, as they solely addressed some characteristics and the importance of different management issues and measures.

Response rate was high $(40.3 \%)$, with 277 respondents completing the survey. 25 invitations (3.5\%) bounced back due to incorrect or non-functioning email addresses. It is likely that the actual response rate was even higher because our list of email addresses probably contained several email addresses of the same persons. Not all of the respondents answered each of the questions, and the 
administration of some questions depended on the answers given to previous questions.

Responses indicate that $67 \%$ of the participants focused regularly or exclusively on sturgeons, with $43 \%$ being involved in sturgeon-related research for more than ten years and $47 \%$ working for 3-10 years. Forty seven percent of the respondents published six or more papers on sturgeons, and $26 \%$ had more than 10 published papers focused on these species. All sturgeon and paddlefish species were represented within the respondents' research foci, although the numbers of respondents that were dealing with the species of the genus Pseudoscaphirhynchus, the Alabama sturgeon (Scaphirhynchus suttkusi) and with Chinese paddlefish (Psephurus gladius) were low, with only 1-4 persons per species. The majority of the respondents (59\%) focused their research on North America, while $29 \%$ and $24 \%$ focused on Europe and Asia, respectively. Such taxonomic and regional differences reflect the overall trends observed in sturgeon and paddlefish research, with the majority of published research being focused on only a fraction of the species, with the endangered species receiving disproportionately less research attention (Jarić and Gessner, 2012; Gessner et al., 2013). Survey of published sturgeon and paddlefish research (Jarić and Gessner, 2012) indicated that it was dominated by North American researchers, especially from the United States, although with a recent shift towards the Eurasian region. However, it was also evident that research in Asia has the potential to surpass the relative contribution of 
research coming from the European Union and the United States (Jarić and Gessner, 2012).

The participants covered a wide range of research fields (Fig. 1), with a focus on conservation and ecology, which was in line with the topic of the survey. Research foci differed depending on the regions that the respondents originated from. Conservation was ranked as the dominant research field in all three continents, while the other fields revealed substantial variations in importance across the regions. In North America, dominant topics included ecology, distribution and migrations, fisheries management, habitat restoration and modeling. Researchers in Europe focused on fisheries management and reproduction, particularly ex-situ measures, including caviar trade and trade regulations. In Asia, main areas of research included physiology and bioenergetics, with a comparatively higher proportion of researchers working on genetics, fish nutrition, and rearing techniques (Fig. 1).

Senescence

Senescence is defined as an inherent reduction of fecundity or complete loss of reproduction ability in old age, or alternatively as the maximum reproductive age that occurs before the maximum longevity has been reached, or finally as the existence of post-reproductive lifespan (Reznick et al., 2006; Jarić et al., 2010). Two thirds of the researchers $(65 \%)$ were uncertain as to whether sturgeons and paddlefish experience senescence. Of the group of respondents that had an opinion 
on this issue, the larger proportion (59\%) supported the concept of senescence in Acipenseriformes (21\% of all the respondents; Fig. 2). In their individual responses, some of the respondents stated that they considered senescence as unlikely because there are records of larger, older individuals that were making spawning migrations, while others indicated that there are some indications of a slight decrease in fecundity at older age.

The issue of senescence is only rarely raised or touched upon in studies and reviews dealing with sturgeon and paddlefish ecology. Nevertheless, authors have reported or claimed either a lack of senescence or at least a lack of evidence on senescence in different sturgeon species, such as white sturgeon (Acipenser transmontanus; Hildebrand et al., 2016), Gulf sturgeon (A. oxyrinchus desotoi; Sulak et al., 2016), and pallid sturgeon (Scaphirhynchus albus; Jordan et al., 2016).

According to Reznick et al. (2002), fish evolution tends to promote delayed senescence due to indeterminate growth, and due to the resulting substantial increase in fecundity with age. As such, the relative contribution of the spawning potential of older age-classes increases. Delayed maturity additionally stimulates evolution of delayed senescence, as it has to be compensated with high fecundity and longer reproductive lifespan (Tsoukali et al., 2016). Webb (2003) stated that fertility in old females does not decline. According to Sulak et al. (2016), there are no indications of female gonadal senescence in any of the sturgeon species in the wild. Moreover, in lake (A. fulvescens) and white sturgeon, interspawning interval does not change with age (Webb, 2003; Forsythe et al., 2012). 
While true reproductive senescence, as a complete cessation of reproduction, does not appear to occur in sturgeon, there are indices of a partial senescence. Webb (2003) claimed that a slight decrease in fecundity does occur with age, which could be interpreted as partial reproductive senescence in sturgeon. One of the rare reports of senescence in sturgeon is a study by Williot et al. (2005), who observed senescence in aquaculture populations of sterlet (A. ruthenus). Croft et al. (2015) claimed that senescence and prolonged post-reproductive lifespans in fish are rare and occur only in captivity, either through increased lifespans due to decreased mortality in captive conditions, or through accelerated reproductive senescence caused by breeding programmes.

While the survey indicated a high level of respondent uncertainty regarding the importance of senescence in undisturbed populations (41\%), a higher proportion of respondents that had an opinion on this issue considered it as important (Fig. 2). Higher importance of senescence was perceived within the group classified as experienced researchers (40\%), as well as by European (31\%) and Asian researchers (42\%), while it was considered less relevant by the respondents from North America (23\%). The question of senescence in sturgeons is relevant for management and conservation planning, as it indicates the importance of maintaining older individuals in a population. Without senescence in sturgeons, high reproductive potential of older age-classes could compensate for their low relative abundance. As such, the question of senescence is often encountered by population modellers. Due to a lack of data, it is common practice by researchers to assume lack 
of senescence in sturgeons when constructing population models (Vélez-Espino and Koops, 2009; Steffensen et al., 2013; Jarić et al., 2015). However, a false assumption about senescence in population models affects the resulting reproductive potential of the population and the model inferences, such as the number of reproductive adults needed for a population to remain viable (Steffensen et al., 2013). The highest level of uncertainty regarding the presence of senescence in sturgeons was expressed by respondents from North America, which was also revealed as the region with the most intensive use of population models (Jarić et al., 2015). As a result, it would be both relevant and beneficial if researchers from this region would make a special effort to address this gap in information.

The issue of senescence requires further studies. However, such efforts are likely to be hindered by a lack of undisturbed populations with older individuals, as well as by a presence of different anthropogenic impacts, such as pollution, which might produce effects that resemble those of senescence. It is likely that such masking effects of pollution and other anthropogenic impacts, as well as difficulties in observing senescence characterized by a gradual decrease in reproductive effectiveness, probably influenced the level of uncertainty expressed by the respondents. An additional problem is that research of senescence requires lethal sampling (Webb, 2003). A detailed discussion of potential methods to determine and monitor the occurrence of reproductive senescence in sturgeons was presented by Webb (2003). 


\section{Mating type}

Polyandry was identified as the common mating type in sturgeons and paddlefish by $43 \%$ of all respondents, and by the majority of experienced researchers $(58 \%)$ and researchers working in the field of ecology $(57 \%)$. Some authors referred to field data to support polyandric mating type, while some claimed that the common mating type might differ among species. The majority of North American researchers (53\%) cited polyandric mating as the dominant type, while only $36 \%$ of European researchers held the same view. Asian responses indicated that the most common mating type is mixed polygamous mating, with irregular spawning batches (20\%; Fig. 3). Nearly one third of the respondents (29\%) were uncertain as to how to answer the question.

Spawning behavior in most of the sturgeon species is difficult to observe, because spawning occurs in deep and sometimes turbid rivers (Hildebrand et al., 2016). Polyandrous spawning, represented by several males following a single female and competing for optimum spawning position, was reported in a number of species such as Atlantic sturgeon (A. o. oxyrinchus; Hilton et al., 2016), Gulf sturgeon (Sulak et al., 2016), shortnose sturgeon (A. brevirostrum; Kynard et al., 2016), and white sturgeon (Hildebrand et al., 2016). However, males also tend to remain near the spawning grounds, and spawn several times with different females (Sulak et al., 2016). This was confirmed by a long-term study of lake sturgeon, which indicated that their spawning is essentially polygamous, with several males and a single female commonly participating in the actual spawning event, while each 
male may consequently participate in additional spawning events with other females (Bruch and Binkowski, 2002). Furthermore, pedigree analysis of white sturgeon indicated a mixed, polygynandrous mating system, with about 1-6 spawning partners per fish (Hildebrand et al., 2016). According to Pollock et al. (2015), polyandrous and polygynous mating systems are both present in sturgeon. As noted by Hildebrand et al. (2016), as well as by some respondents from the present survey, spawning events at low population abundances are often represented by a single pair of fish.

\section{Homing behavior}

A set of questions was dealing with the strength and major drivers of spawning site fidelity, which can be defined an affinity for natal areas and sites in spawning habitat choice (Pollock et al., 2015). The majority of the respondents $(59 \%)$ considered sturgeons and paddlefish to be semi-opportunistic regarding their spawning site fidelity, that is, these fish tend to migrate towards the same spawning site, but they also readily use other sites, based on circumstances (Fig. 4). This was an even more dominating response among the experienced researchers (68\%) and those working in the field of ecology $(69 \%)$.

There is abundant evidence of spawning site fidelity in various sturgeon species (DeHaan et al., 2006; Welsh et al., 2008; Forsythe et al., 2012; Pollock et al., 2015; Bruch et al., 2016; Kynard et al., 2016; Sulak et al., 2016). In addition, differentiated genetic structure observed in some populations with no visible 
fragmentation is considered to be another indication of a strong spawning site fidelity (Pollock et al., 2015; Bruch et al., 2016; Hildebrand et al., 2016; Sulak et al., 2016). Subpopulation differentiation in spawning site selection and repeatability can develop even within smaller systems (Forsythe et al., 2012). However, while pronounced spawning site fidelity in sturgeons is likely, they also tend to switch between different sites within and among rivers between years, and in some cases even within the same year (Bruch et al., 2016; Sulak et al., 2016). As hypothesized by Hilton et al. (2016), straying and spawning in non-natal rivers represents an important mechanism for gene-flow among subpopulations, as well as for colonization of areas with extirpated populations. According to Bruch et al. (2016), spawning site fidelity seems to be relatively weaker in systems with higher number of spawning sites, and there is even a possibility that the apparent strong site fidelity observed in some species may have resulted merely from a limited number of suitable spawning sites within the river (Bruch et al., 2016).

In contrast to the question on the presence of homing, there was no clear agreement on the major drivers of homing behavior (Fig. 4). About one third of the respondents (35\%) were not sure concerning this issue. The percentage of respondents claiming that the early life stage imprinting represents the key driver (31\%) was slightly higher than the percentage of those that claimed a combination of early life stage imprinting and genetic factors (26\%) occurred. Furthermore, experienced researchers almost evenly selected the two mentioned responses (33\% and $34 \%$, respectively). Respondent uncertainty was especially pronounced among 
North American researchers (47\%), while European researchers opted more strongly for the early life stage imprinting as the key homing driver (47\%). As one may predict, researchers dealing with genetics had a comparatively higher percentage of responses that supported genetic factors as the key homing driver (14\%) than those dealing with other research fields (7\%). Several authors also suggested social learning as another potential homing mechanism.

The selection of the location and time of spawning in fish have been generally attributed to genetics, physiology, age, size, olfactory cues and in a few cases other factors (Forsythe et al., 2012). Spawning site fidelity in sturgeons seems to be driven to some extent by genetics, whose impact can, however, differ in its strength among populations (Kynard et al., 2016). On the other hand, according to some authors, the phenomenon of juveniles participating in spawning migrations of adult sturgeons (Holčik, 1989) might be driven by the necessity of juveniles to either acquire behavior or chemically imprint upon habitat sites, which, if true, would indicate the importance of early life-stage imprinting factors (Sulak and Randall, 2002; Kynard et al., 2016; Sulak et al., 2016).

Nearly half of the respondents were not sure about the influence of gender on homing behavior (44\%). Of those that had an opinion on this issue, a majority believed that homing behavior is either equally strong in females and males, or stronger in females ( $37 \%$ and $19 \%$ of the total sample, respectively). In Gulf sturgeon, females have a pronounced fidelity towards a specific spawning site and can be very selective regarding the spawning ground location (Sulak et al., 2016). 
Spawning site fidelity is mostly assessed through mark-recapture and telemetry studies. However, given that the duration of such studies has been relatively short, it remains unknown whether the observed patterns of strong spawning site fidelity represent life-long or transitory patterns (Hildebrand et al., 2016). The question of spawning site and natal river fidelity, its strength and mechanisms, is to a large extent still unresolved and requires further studies (Pikitch et al., 2005; Hilton et al., 2016; Sulak et al., 2016).

\section{Longevity}

When asked about their opinion on reports of sturgeon lifespans as high as $100-150$ years in some species, respondents were evenly distributed between those who assumed such reports to be mostly true for undisturbed populations (34\%) and those claiming that they may be true only in few cases (36\%). Individual comments were also largely controversial between researchers claiming that such longevities are true or even underestimations of potential lifespans in sturgeons, and those claiming that such lifespans are just extreme, rare events, likely to be attained by only a few individuals.

Reports on extreme lifespans gained higher support among the species experts than among the respondents not dealing with those species ("other respondents"; Fig. 5). For example, the lifespan of 118 years reported in beluga (Huso huso; Billard and Lecointre, 2001) was supported by $81 \%$ of experts for this species, while it was supported by only $44 \%$ of all the other respondents. An even 
higher difference in opinion between the two groups was observed for the reports on lifespans of 100 years or more in European sturgeon (Acipenser sturio; Jarić and Gessner, 2013), with $75 \%$ of species experts supporting such reports compared to $33 \%$ of the other respondents. Extreme lifespan of 154 years in lake sturgeon (Haxton et al., 2016) received the lowest support, both from experts (46\%) and the other respondents (15\%; Fig. 5), even though this report was based on a valid and generally reliable assessment method. Lifespans of 104 years in white sturgeon (Rien and Beamesderfer, 1994; Billard and Lecointre, 2001) and of more than 100 years in Atlantic sturgeon (inferred from the age at maturity in northern populations; Jarić and Gačić, 2012), were supported by $69 \%$ and $56 \%$ of species experts and 36\% and $28 \%$ of other respondents, respectively.

An important question is whether the observed longevities predominantly represent the exception or the rule in sturgeon populations (Pollock et al., 2015). Sulak and Randall (2002) have argued against reported extreme lifespans, and claimed that such individuals are rare and their contribution to the population is only minor. Similarly, Pollock et al. (2015) discussed the question of long lifespans observed in lake sturgeon, providing some evidence that they may not be as longlived as generally thought. However, it is important to note that most of the evidence on lower lifespans in sturgeons and paddlefish, presented by these and other authors (i.e., 48 years in European sturgeon and 60 years in Atlantic sturgeon; Billard and Lecointre, 2001), originates from disturbed populations. Apparent absence of older individuals in contemporary populations is likely driven by historic overfishing that 
was targeting mature fish (Pollock et al., 2015), and the observed longevity in exploited populations tends to decline significantly (Jarić and Gačić, 2012; Tsoukali et al., 2016). A population model of the European sturgeon indicated that fishing mortalities as low as 5\% can reduce previously undisturbed populations to no more than $20-30 \%$ of their historic spawning biomass, mainly on the expense of older ageclasses (Jarić and Gessner, 2013). Reliable longevity estimates require access to undisturbed sturgeon populations, which are rare (Jarić and Gačić, 2012; Haxton and Cano, 2016). According to (Bruch et al., 2016), long-term tagging studies have demonstrated that lake sturgeon have a potential for extended lifespans, and that ages of more than 150 years are not unreasonable. It is also worth noting that standard age assessments based on bony structures tend to underestimate true age (Bruch, 2008).

According to Reznick et al. (2002), long lifespan can be attained through the combination of low extrinsic mortality rates and delayed senescence, and additionally facilitated by age-specific increases in fecundity. A long lifespan represents an important adaptive trait in sturgeons and paddlefish, which allows numerous opportunities to spawn while reducing the need to spawn in years with unsuitable conditions (Beamesderfer and Farr, 1997).

Species longevity represents an important life history parameter, for both fishery and conservation management, and a lack of such data often hinders implementation of effective management and conservation measures (Froese and Binohlan, 2000; Jarić and Gačić, 2012). Incorrect inference of potential lifespans in 
sturgeons can significantly impact population recovery models and management planning targets (Pollock et al., 2015). One of the problems that are complicating age assessments studies in sturgeons is that most of the available methods are invasive, destructive or imprecise (Pollock et al., 2015). The question of potential lifespans in sturgeons requires further long-term research efforts.

\section{Maximum body size}

Compared to the reports on extreme lifespans, respondents were less likely to support the reports on extreme body length and weight in some species (i.e. 6-9 $\mathrm{m}$, and 1-3 tonnes). As much as $50 \%$ of the researchers were convinced that such reports may be true only in a few cases, and that such dimensions are reached only rarely, while $11 \%$ considered them exaggerated and unlikely. Again, species experts generally provided greater support for the reported extreme dimensions than the other respondents (Fig. 6). While the reports on $6 \mathrm{~m}$ and $1500 \mathrm{~kg}$ beluga (Rochard et al., 1991; Holčik, 1989; Reinartz, 2002; Pikitch et al., 2005) received higher support from the species experts than from the other respondents, reports on even larger specimens of $9 \mathrm{~m}$ and $3000 \mathrm{~kg}$ (Holčik, 1989; Rochard et al., 1991; Reinartz, 2002; Vassilev 2006) had comparatively less support by species experts. Reports on kaluga (H. dauricus) specimens of $6 \mathrm{~m}$ and $1000 \mathrm{~kg}$ (Krykhtin and Svirskii, 1997; Chen, 2007) were well supported by species experts, while extreme dimensions in Atlantic sturgeon (5 m; Smith, 1985; Kahnle et al., 2007; Hilton et al., 2016), white sturgeon (6 m and 800 kg; Rochard et al., 1991; Ward, 1998; Billard and Lecointre, 2001) and 
European sturgeon (6 m and 1000 kg; Schoenevelde, 1624; Holčik, 1989; Gessner et al., 2007; Jarić and Gessner, 2013) were supported to a lesser degree (Fig. 6).

As discussed above for the maximum lifespans in sturgeons, opinions on the reliability of historic reports with regard to large dimensions also differ (Sulak and Randall, 2002). However, life history parameters such as body length and weight are likely to be underestimated if assessed under conditions such as longterm heavy exploitation (Jarić and Gessner, 2013). Very few sturgeon populations today, if any, can be considered as truly undisturbed. For those that are effectively protected, the time was far too short to allow full recovery to their historic state.

\section{Population growth rate}

Population growth rate represents the population-specific intrinsic rate of increase, or the per-capita rate at which a particular population is capable of increasing under optimum environmental conditions (Huston, 1979). Intrinsic population growth rate is a difficult parameter to estimate, and especially so in longlived species, such as sturgeons (Dillingham et al., 2016). Reflecting the lack of consensus on the probable intrinsic population growth rate in sturgeons and paddlefish, the majority of respondents (53\%) were unsure about the proper response. This indicates that the concept of the population growth rate is not fully comprehended within the community. Of those who provided an answer to this question, a population growth rate of $5 \%$ or less received the highest proportion of responses ( $27 \%$ of the total sample). Furthermore, such low population growth rates 
were even more strongly supported by experienced researchers $(32 \%)$ and those focused on population ecology and modelling (41\%; Fig. 7). Slow physical growth and discontinuous spawning of sturgeons results in low intrinsic population growth rates (Heppell, 2007). The knowledge on this parameter in sturgeon populations is poor, but the available data indicate that it tends to range from 0.05 to 0.15 , although mostly closer to the lower part of the range (Pine et al., 2001; Bruch, 2008; Jarić et al., 2010).

\section{Inbreeding and outbreeding}

Of all respondents, 56\% agreed with the conviction that inbreeding and outbreeding depressions play an important role as a negative impact in sturgeon populations at low abundances, while $35 \%$ respondents neither agreed nor disagreed with it. The group of respondents who are dealing with population genetics provided the highest degree of agreement (63\%).

All sturgeon and paddlefish are polyploid (Haxton et al., 2016), which should reduce the effects and risks of inbreeding (Galloway et al., 2003; Comai, 2004). Inbreeding is generally considered less critical in fish due to their high fecundity (Ludwig et al., 2009), while sturgeons can be additionally buffered from genetic diversity loss through their longevity and iteroparity (DeHaan et al., 2006). Nevertheless, effective population size of fish species with a high number of offspring can be surprisingly small, as it produces large variance in contribution to the next generation (Hedrick, 2002). 


\section{Sturgeons and paddlefish as surrogate species}

Three types of surrogate concepts often invoked for sturgeons and paddlefish are flagship, umbrella and indicator species. Flagship species represent species with a potential to effectively promote societal awareness and to raise funds for conservation (Veríssimo et al., 2011). Management and conservation measures directed at umbrella species are likely to benefit a wider range of co-occurring species (Fleishman et al., 2000), while indicator species represent organisms whose characteristics can be used as an index of the state of their environment (Caro and O'Doherty, 1999).

More than half of the respondents considered sturgeons and paddlefish as suitable flagship species (55\%) and indicator species (51\%), while their use as umbrella species was relatively poorly supported (29\%). Respondents differed in their opinion and rationale. For instance, there was a higher level of support for their use as surrogate species within those groups of researchers that are using these concepts in practice, such as those focused on the fields of ecology, and policy and management (Fig. 8). Those who considered sturgeons and paddlefish as suitable indicator species explained this by their requirements of good water quality and high oxygen levels, and their body size that makes them easier to monitor, while those that disagreed listed their late maturation and infrequent mating. Those respondents who considered them as species with high flagship potential claimed that they are appealing to general public, while those that disagreed claimed the opposite. There 
was a considerably higher support for their flagship potential among European researchers (71\%), while researchers focused on Asia provided comparatively lower support for their use within each of the three surrogate species types, but especially so regarding their umbrella potential (19\%). It is important to note that there is some confusion within the scientific community regarding these terms (Caro and O'Doherty, 1999), which was explicitly indicated by some respondents. Unclear concepts and notions may add noise to the survey data and thus reduce the clarity of findings.

According to Gessner et al. (2011, 2013), sturgeons and paddlefish match perfectly with the definitions of both flagship and umbrella species due to their wide ranges, diverse habitat requirements and their public appeal. In addition, a number of other authors have emphasized flagship potential of sturgeons and paddlefish in general (e.g. Doukakis et al., 2012; Cooke et al., 2013; Grambow, 2015), while some species have been explicitly indicated as suitable flagship species, such as lake sturgeon (McDermid et al., 2015), Chinese sturgeon (A. sinensis; Kottelat and Whitten, 1996; Fu et al., 2003), European sturgeon (Rochard, 2011) and Chinese paddlefish (Mims, 2015). They have also been advocated as flagship species by various organizations, such as World Wildlife Fund (WWF) and International Commission for the Protection of the Danube River (ICPDR; Kalinkat et al., 2017). Sturgeons have also been proposed as umbrella species for river management in Germany (Gessner et al., 2011, 2013). 
The potential of sturgeons to be used as indicator species has not been adequately assessed so far, except for some studies that were focused on the use of sterlet for aquatic pollution monitoring (Poleksic et al., 2010; Lenhardt et al., 2014). Sturgeons and paddlefish are sensitive to habitat fragmentation, changes in water flow, siltation and water and sediment pollution (Gessner et al., 2013). According to Beamesderfer and Farr (1997), "sturgeon also serve as very large canaries in the coal mine of riverine ecosystems".

\section{Major threats}

Based on respondents' ranking of major anthropogenic threats, dam construction and habitat fragmentation were identified as the major threats faced by sturgeons and paddlefish, followed by poor habitat quality, poaching, and insufficient water quality and pollution, and lastly bycatch (Fig. 9). Regional differences in the perception of threats were notable. In contrast to the overall responses (skewed by the large proportion of North American respondents), European and Asian respondents indicated poaching as the major threat, while dams and habitat fragmentation were perceived as the major threat by North American researchers. Pollution had a comparatively higher score in Asia, while bycatch had a higher score in both Europe and Asia (Fig. 9). According to Haxton and Cano (2016), habitat fragmentation represents the largest problem in North America. In a survey conducted within a small group of Eurasian researchers dealing with sturgeons (i.e., co-authors of the study), Williot et al. (2002) determined that the 
main threats in Eurasia were overfishing, pollution, damming, and poaching. The majority of those respondents were sceptical, however, whether it is possible to rank the causes of the sturgeon declines (Williot et al., 2002).

\section{Effects of aquaculture production on alleviating pressure on natural populations}

Reduction in sturgeon caviar and meat supply from the wild, and the high demand and price of caviar, have resulted in a rapid development of sturgeon aquaculture worldwide, with China, USA, Russian Federation and European Union being major producers (Bronzi and Rosenthal, 2014). When asked whether the development of worldwide sturgeon aquaculture for meat and caviar production could have a substantial positive effect on natural populations, $63 \%$ of the respondents answered affirmative, with $42 \%$ of the respondents agreeing and $21 \%$ strongly agreeing. The proportion of respondents that answered positive was somewhat higher among experienced researchers (65\%), and substantially higher among researchers dealing with sturgeon aquaculture (71\%) and caviar trade (82\%), out of which groups those that strongly agreed represented $25 \%, 36 \%$ and $35 \%$, respectively. Massive development of sturgeon aquaculture, as one of the major mitigation strategies for overfishing and poaching of wild stocks, was also recommended by numerous scientists (Billard and Lecointre, 2001; Pikitch et al., 2005; Bronzi et al., 2011). Sturgeon aquaculture can provide a benefit to wild populations by filling the gaps in supply resulting from decline in fishery production. With a vast expansion of sturgeon aquaculture meeting a limited market, 
the resulting decrease in caviar prices can ultimately make illegal trade less attractive (Bronzi et al., 2011).

Some of the respondents who did not answer positively to this question argued that the development of a market for sturgeon aquaculture might create an opening for illegal harvest, especially as an entrance into the market chain for wild fish caviar. According to Raymakers (2006), the development of sturgeon aquaculture might increase risk of laundering wild specimens through such commercial channels. As such, more concise regulations and controls are required to ensure compliance. Aquaculture can also represent an important source of introductions of exotic species, exotic genotypes, diseases and parasites, as well as of pollution (Arndt et al., 2002; Pikitch et al., 2005; Ludwig et al., 2009).

Pikitch et al. (2005) emphasized the need for targeted public education and awareness campaigns, which would shift demand away from the most highly endangered species, as well as reduce overall demand. Additionally, development and production of caviar substitutes, such as caviar from other non-sturgeon and non-fish species, such as snails, and caviar-resembling products, could have an additional positive effect in combating demand for caviar (Bronzi and Rosenthal, 2014).

\section{Effectiveness of international legislation}

Scoring of the international conventions based on their effectiveness regarding sturgeon and paddlefish protection, restoration and sustainable 
management indicated that only the Convention on International Trade in Endangered Species of Wild Fauna and Flora (CITES) had a good overall score, while all other conventions received moderate scores (Fig. 10). The United Nations Convention on the Law of the Sea (UNCLOS) had the lowest score. A significant proportion of respondents was unsure about the effectiveness of any of the conventions, except for CITES. This was especially present among the North American researchers, where as much as $80 \%$ of respondents could not provide a score to any of the conventions, again with the exception of CITES.

CITES probably represents the most significant international act protecting sturgeons and paddlefish, and one of the major steps in their conservation was the listing of sturgeon species on Annex II of CITES in Harare in 1997 (Pikitch et al., 2005; Bronzi et al., 2011). Some of the major contributions of CITES were a system of export quotas, an universal labelling system for the identification of caviar, international cooperation and harmonization of management and conservation measures, joint stock assessment and enhancement, and an improved monitoring and reporting (Raymakers, 2006).

\section{Respondent uncertainty}

Different topics and questions indicated varying levels of respondent uncertainty, which were in some cases substantial (Fig. 11). As can be seen in the figure, experienced researchers were consistently less unsure in their responses, which might indicate that they either had more knowledge or more established 
beliefs regarding these topics. Respondent uncertainty was in some cases likely driven by a lack of clarity regarding some terms or a lack of their definitions, as in the case of the surrogate species concepts, but they also represent a lack of knowledge and understanding regarding some of the key issues on sturgeon life history and management. As indicated in Fig. 11, the highest level of uncertainty was related to the questions about senescence, population growth rates and homing behavior.

\section{Conclusion}

Our study revealed substantial knowledge gaps in sturgeon ecology and life history among sturgeon and paddlefish researchers. It also indicated striking differences in beliefs and opinions held within the scientific community. Convictions differed among regions, research fields and research experience. Based on the observed gaps in knowledge and data, some of the critical topics for future research would be those dealing with senescence, homing behavior and homing drivers, natural population growth rates, natural mortality and potential lifespans. Because the apparent lack of understanding of the real population growth rates might impede future development of effective management measures, this issue should represent one of the highest research priorities (Jarić et al., 2010). Further work is also needed with regard to the issue of sturgeon lifespans, especially regarding the question of the relative abundance of old specimens in a population (Pollock et al., 2015). Until more reliable data become available, longevity, maximum body size and other basic 
parameters can be inferred through different proxies and relationships with other life history traits (Jarić and Gačić, 2012; Kenchington, 2014; Nadon and Ault, 2016). Our results differ from those obtained by Williot et al. (2002) in their survey among sturgeon researchers, who stated that the biology and ecology of sturgeons were sufficiently known to provide suitable recommendations for a sustainable management of sturgeon populations.

Sturgeon and paddlefish research is still characterized by a relatively low level of international cooperation (Jarić and Gessner, 2012). As the research focuses on extremely long-lived and rare species, there is a need for improved and organized data sharing, especially of raw data on sturgeons (Pollock et al., 2015), as well as for improved funding for management and research (Gessner et al., 2013). As suggested by Pollock et al. (2015), researchers should be encouraged to publish data either through peer reviewed literature, or through a common online database established for such purpose.

\section{Acknowledgements}

We are deeply indebted to all sturgeon researchers who completed the survey and provided many valuable comments and suggestions. We would also like to thank two anonymous reviewers for providing valuable comments and suggestions that helped us to improve our article. The authors also acknowledge the sponsorship provided by the Alexander von Humboldt Foundation and the Federal German Ministry for Education and Research, as well as the support by the Project 
No. 173045, funded by the Ministry of Education, Science and Technological Development of the Republic of Serbia.

\section{References}

Arndt, G. M., Gessner, J., \& Raymakers, C. (2002). Trends in farming, trade and occurrence of native and exotic. sturgeons in natural habitats in Central and Western Europe. Journal of Applied Ichthyology, 18(4-6), 444-448.

Beamesderfer, R. C., \& Farr, R. A. (1997). Alternatives for the protection and restoration of sturgeons and their habitat. Environmental Biology of Fishes, 48, 407417.

Bemis, W. E., \& Kynard, B, (1997). Sturgeon rivers: an introduction to acipenseriform biogeography and life history. Environmental Biology of Fishes, 48, 167-183.

Billard, R., \& Lecointre, G. (2001). Biology and conservation of sturgeon and paddlefish. Reviews in Fish Biology and Fisheries, 10(4), 355-392.

Bronzi, P., \& Rosenthal, H. (2014). Present and future sturgeon and caviar production and marketing: a global market overview. Journal of Applied Ichthyology, 30(6), 1536-1546. 
Bronzi, P., Rosenthal, H., \& Gessner, J. (2011). Global sturgeon aquaculture production: an overview. Journal of Applied Ichthyology, 27(2), 169-175.

Bruch, R. M. (2008). Modeling the population dynamics and sustainability of lake sturgeon in the Winnebago system, Wisconsin. Dissertation, University of Wisconsin-Milwaukee.

Bruch, R. M., \& Binkowski, F. P. (2002). Spawning behavior of lake sturgeon (Acipenser fulvescens). Journal of Applied Ichthyology, 18(4-6), 570-579.

Bruch, R. M., Haxton, T. J., Koenigs, R., Welsh, A., \& Kerr, S. J. (2016). Status of Lake Sturgeon (Acipenser fulvescens Rafinesque 1817) in North America. Journal of Applied Ichthyology, 32(S1), 162-190.

Caro, T. M., \& O'Doherty, G. (1999). On the use of surrogate species in conservation biology. Conservation Biology, 13(4), 805-814.

Chen, X. (2007). The biology and resources of Acipenseriformes. China Ocean Press. 
Comai, L. (2005). The advantages and disadvantages of being polyploid. Nature Reviews Genetics, 6(11), 836-846.

Cooke, S. J., Lapointe, N. W. R., Martins, E. G., Thiem, J. D., Raby, G. D., Taylor, M. K., Beard Jr., T. D., \& Cowx, I. G. (2013). Failure to engage the public in issues related to inland fishes and fisheries: strategies for building public and political will to promote meaningful conservation. Journal of Fish Biology, 83(4), 997-1018.

Croft, D. P., Brent, L. J., Franks, D. W., \& Cant, M. A. (2015). The evolution of prolonged life after reproduction. Trends in Ecology \& Evolution, 30(7), 407-416.

Das, M., Ester, P., \& Kaczmirek, L. (Eds.) (2011). Social and behavioral research and the internet. New York: Routledge.

DeHaan, P. W., Libants, S. V., Elliott, R. F., \& Scribner, K. T. (2006). Genetic population structure of remnant lake sturgeon populations in the upper Great Lakes basin. Transactions of the American Fisheries Society, 135(6), 1478-1492.

Dillingham, P. W., Moore, J. E., Fletcher, D., Cortés, E., Curtis, K. A., James, K. C., \& Lewison, R. L. (2016). Improved estimation of intrinsic growth rmax for longlived species: integrating matrix models and allometry. Ecological Applications, 26(1), 322-333. 
Dillman, D. A., Smyth, J. D., \& Christian, L. M. (2014). Internet, Phone, Mail, and Mixed-Mode Surveys. Hoboken, NJ: Wiley \& Sons.

Doukakis, P., Pikitch, E. K, Rothschild, A., DeSalle, R., Amato, G., \& Kolokotronis, S. O. (2012). Testing the effectiveness of an international conservation agreement: marketplace forensics and CITES caviar trade regulation. PloS One, 7(7), e40907.

Fleishman, E., Murphy, D. D., \& Brussard, P. F. (2000). A new method for selection of umbrella species for conservation planning. Ecological Applications, 10, 569579.

Forsythe, P. S., Crossman, J. A., Bello, N. M., Baker, E. A., \& Scribner, K. T. (2012). Individual-based analyses reveal high repeatability in timing and location of reproduction in lake sturgeon (Acipenser fulvescens). Canadian Journal of Fisheries and Aquatic Sciences, 69(1), 60-72.

Froese, R., \& Binohlan, C. (2000). Empirical relationships to estimate asymptotic length, length at first maturity and length at maximum yield per recruit in fishes, with a simple method to evaluate length frequency data. Journal of Fish Biology, 56(4), 758-773. 
Fu, C., Wu, J., Chen, J., Wu, Q., \& Lei, G. (2003). Freshwater fish biodiversity in the Yangtze River basin of China: patterns, threats and conservation. Biodiversity and Conservation, 12(8), 1649-1685.

Galloway, L. F., Etterson, J. R., \& Hamrick, J. L. (2003). Outcrossing rate and inbreeding depression in the herbaceous autotetraploid, Campanula americana. Heredity, 90(4), 308-315.

Gessner, J., Van Eenennaam, J. P., \& Doroshov, S. I. (2007). North American green and European Atlantic sturgeon: comparisons of life histories and human impacts. Environmental Biology of Fishes, 79(3), 397-411.

Gessner, J., Tautenhahn, M., Spratte, S., Arndt, G. M., \& von Nordheim, H. (2011). Development of a German Action Plan for the restoration of the European sturgeon Acipenser sturio L.-implementing international commitments on a national scale. Journal of Applied Ichthyology, 27(2), 192-198.

Gessner, J., Jarić, I., Rochard, E., \& Pourkazemi, M. (2013). Sturgeon and paddlefish research focuses on low risk species and largely disregards endangered species. Endangered Species Research, 22, 95-97. 
Grambow, M. G. (2015). Experiences from the International Rhine Water Management. Strategic Analysis, 39(1), 9-15.

Haxton, T. J., \& Cano, T. M. (2016). A global perspective of fragmentation on a declining taxon - the sturgeon (Acipenseriformes). Endangered Species Research, $31,203-210$.

Haxton, T. J., Sulak, K., \& Hildebrand, L. (2016). Status of scientific knowledge of North American sturgeons. Journal of Applied Ichthyology, 32(S1), 5-10.

Hedrick, P. W. (2002). Application of molecular genetics to conservation: new issues and examples. In: Beissinger, R., McCullough, D. R. (eds) Population Viability Analysis. Chicago \& London: The University of Chicago Press, 367-387.

Heppell, S. S. (2007). Elasticity analysis of green sturgeon life history. Environmental Biology of Fishes, 79(3-4), 357-368.

Hildebrand, L. R., Drauch Schreier, A., Lepla, K., McAdam, S. O., McLellan, J., Parsley, M. J., Paragamian, V. L., \& Young, S. P. (2016). Status of White Sturgeon (Acipenser transmontanus Richardson, 1863) throughout the species range, threats to survival, and prognosis for the future. Journal of Applied Ichthyology, 32(S1), 261-312. 
Hilton, E. J., Kynard, B., Balazik, M. T., Horodysky, A. Z., \& Dillman, C. B. (2016). Review of the biology, fisheries, and conservation status of the Atlantic Sturgeon, Acipenser oxyrinchus oxyrinchus Mitchill, 1815. Journal of Applied Ichthyology, $32(\mathrm{~S} 1), 30-66$.

Holčik, J. (ed) (1989). The freshwater fishes of Europe. Wiesbaden, Germany: AULA Verlag.

Huston, M. (1979). A general hypothesis of species diversity. The American Naturalist, 113(1), 81-101.

IUCN (2016). The IUCN Red List of Threatened Species. Version 2016-3. Retreived from: http://www.iucnredlist.org

Jarić, I., \& Gačić, Z. (2012). Relationship between the longevity and the age at maturity in long-lived fish: Rikhter/Efanov's and Hoenig's methods. Fisheries Research, 129, 61-63.

Jarić, I., \& Gessner, J. (2012). Analysis of publications on sturgeon research between 1996 and 2010. Scientometrics, 90(2), 715-735. 
Jarić, I., \& Gessner, J. (2013). A life-stage population model of the European sturgeon (Acipenser sturio) in the Elbe River. Part I: general model outline and potential applications. Journal of Applied Ichthyology, 29(3), 483-493.

Jarić, I., Lenhardt, M., Cvijanović, G., \& Ebenhard, T. (2009). Population viability analysis and potential of its application to Danube sturgeons. Archives of Biological Sciences, 61(1), 123-128.

Jarić, I., Ebenhard, T., \& Lenhardt, M. (2010). Population viability analysis of the Danube sturgeon populations in a Vortex simulation model. Reviews in Fish Biology and Fisheries, 20(2), 219-237.

Jarić, I., Gessner, J., \& Lenhardt, M. (2015). A life-table metamodel to support the management of data deficient species, exemplified in sturgeons and shads. Environmental Biology of Fishes, 98(12), 2337-2352.

Jordan, G. R., Heist, E. J., Braaten, P. J., DeLonay, A. J., Hartfield, P., Herzog, D. P., Kappenman, K. M., \& Webb, M. A. H. (2016). Status of knowledge of the Pallid Sturgeon (Scaphirhynchus albus Forbes and Richardson, 1905). Journal of Applied Ichthyology, 32(S1), 191-207. 
Kahnle, A. W., Hattala, K. A., \& McKown, K. A. (2007). Status of Atlantic sturgeon of the Hudson River Estuary, New York, USA. American Fisheries Society Symposium, 56, 347-363.

Kalinkat, G., Cabral, J. S., Darwall, W., Ficetola, G. F., Fisher, J. L., Giling, D., Gosselin, M. P., Grossart, H. P., Jähnig, S. C., Jeschke, J. M., Knopf, K., Larsen, S., Onandia, G., Paetzig, M., Saul, W. C., Singer, G., Sperfeld, E., \& Jarić, I. (2017). Flagship umbrella species needed for the conservation of overlooked aquatic biodiversity. Conservation Biology, 31(2), 481-485.

Kenchington, T. J. (2014). Natural mortality estimators for information-limited fisheries. Fish and Fisheries, 15(4), 533-562.

Kottelat M., \& Whitten T. (1996). Freshwater biodiversity in Asia: with special reference to fish. World Bank Publications.

Krykhtin, M. L., \& Svirskii, V. G. (1997). Endemic sturgeons of the Amur River: kaluga, Huso dauricus, and Amur sturgeon, Acipenser schrenckii. Environmental Biology of Fishes, 48, 231-239.

Kynard, B., Bolden, S., Kieffer, M., Collins, M., Brundage, H., Hilton, E. J., Litvak, M., Kinnison, M. T., King, T., \& Peterson, D. (2016). Life history and status of 
shortnose sturgeon (Acipenser brevirostrum LeSueur, 1818). Journal of Applied Ichthyology, 32(S1), 208-248.

Lenhardt, M., Smederevac-Lalić, M., Djikanović, V., Cvijanović, G., VukovićGačić, B., Gačić, Z., \& Jarić, I. (2014). Biomonitoring and genetic analysis of sturgeons in Serbia - a contribution to their conservation. Acta Zoologica Bulgarica, $S 7,69-73$.

Ludwig, A., Lippold, S., Debus, L., \& Reinartz, R. (2009). First evidence of hybridization between endangered sterlets (Acipenser ruthenus) and exotic Siberian sturgeons (Acipenser baerii) in the Danube River. Biological Invasions, 11(3), 753760.

McDermid, J., Browne, D., Chetkiewicz, C. L., \& Chu, C. (2015). Identifying a suite of surrogate freshwaterscape fish species: a case study of conservation prioritization in Ontario's Far North, Canada. Aquatic Conservation: Marine and Freshwater Ecosystems, 25(6), 855-873.

Mims, S. D. (2015). Paddlefish: International Status. In: Mims, S. D., \& Shelton, W. L. (eds). Paddlefish Aquaculture. John Wiley \& Sons, Inc, 153-178. 
Nadon, M. O., \& Ault, J. S. (2016). A stepwise stochastic simulation approach to estimate life history parameters for data-poor fisheries. Canadian Journal of Fisheries and Aquatic Sciences, 73(12), 1874-1884.

Pikitch, E. K., Doukakis, P., Lauck, L., Chakrabarty, P., \& Erickson, D. L. (2005). Status, trends and management of sturgeon and paddlefish fisheries. Fish and Fisheries, 6(3), 233-265.

Pine III, W. E., Allen, M. S., \& Dreitz, V. J. (2001). Population viability of the Gulf of Mexico sturgeon: inferences from capture-recapture and age-structured models. Transactions of the American Fisheries Society, 130(6), 1164-1174.

Poleksic, V., Lenhardt, M., Jaric, I., Djordjevic, D., Gacic, Z., Cvijanovic, G., \& Raskovic, B. (2010). Liver, gills, and skin histopathology and heavy metal content of the Danube sterlet (Acipenser ruthenus Linnaeus, 1758). Environmental Toxicology and Chemistry, 29(3), 515-521.

Pollock, M. S., Carr, M., Kreitals, N. M., \& Phillips, I. D. (2014). Review of a species in peril: what we do not know about lake sturgeon may kill them. Environmental Reviews, 23(1), 30-43. 
Raymakers, C. (2006). CITES, the Convention on International Trade in Endangered Species of Wild Fauna and Flora: its role in the conservation of Acipenseriformes. Journal of Applied Ichthyology, 22(S1), 53-65.

Reinartz, R. (2002). Sturgeons in the Danube River. Biology, status, conservation. Literature study. International Association for Danube Research (IAD), Bezirk Oberpfalz, Landesfischereiverband Bayern, e.V.

Reznick, D., Ghalambor, C., \& Nunney, L. (2002). The evolution of senescence in fish. Mechanisms of Ageing and Development, 123(7), 773-789.

Reznick, D., Bryant, M., \& Holmes, D. (2006). The evolution of senescence and post-reproductive lifespan in guppies (Poecilia reticulata). PLoS Biology, 4(1), e7.

Rien, T. A., \& Beamesderfer, R. C. (1994). Accuracy and precision of white sturgeon age estimates from pectoral fin rays. Transactions of the American Fisheries Society, $123(2), 255-265$.

Rochard, E. (2011). Present legal status of the European sturgeon Acipenser sturio. In: Williot, P. et al. (eds) Biology and conservation of the European sturgeon Acipenser sturio L. 1758. Berlin-Heidelberg: Springer, 251-255. 
Rochard, E., Williot, P., Castelnaud, G., \& Lepage, M. (1991). Eléments de systématique et de biologie des populations sauvages d'esturgeons. Acipenser. Antony: Cemagref, 475-507.

Schoenevelde, S. (1624). Ichthyologia et nomenclatvrce animalium marinarum, fluviatilium, lacustrium quce in Florentissimis ducatibus Slesvici et Holsatioe and celeberrimo Emporio Hamburgo occurrent triviales: ac plerorumâq bactenus desideratorum imagines, breves descriptiones, \& explicationes. Ex Bibliopolio Heringiano in Hamburgi.

Smith, T. I. (1985). The fishery, biology, and management of Atlantic sturgeon, Acipenser oxyrhynchus, in North America. Environmental Biology of Fishes, 14(1), 61-72.

Steffensen, K. D., Pegg, M. A., \& Mestl, G. (2013). Population prediction and viability model for pallid sturgeon (Scaphirhynchus albus, Forbes and Richardson,) in the lower Missouri River. Journal of Applied Ichthyology, 29(5), 984-989.

Sulak, K. J., \& Randall, M. (2002). Understanding sturgeon life history: enigmas, myths, and insights from scientific studies. Journal of Applied Ichthyology, 18(4-6), 519-528. 
Sulak, K. J., Parauka, F., Slack, W. T., Ruth, R. T., Randall, M. T., Luke, K., Mettee, M. F., \& Price, M. E. (2016). Status of scientific knowledge, recovery progress, and future research directions for the Gulf Sturgeon, Acipenser oxyrinchus desotoi Vladykov, 1955. Journal of Applied Ichthyology, 32(S1), 87-161.

Tsoukali, S., Olsson, K. H., Visser, A. W., \& MacKenzie, B. R. (2016). Adult lifetime reproductive value in fish depends on size and fecundity type. Canadian Journal of Fisheries and Aquatic Sciences, 73(9), 1405-1412.

Vassilev, M. (2006). Lower Danube - the last refuge for surviving of sturgeon fishes in the Black Sea Region. In: Hubert, P. (ed) Water observation and information system for decision support. Conference Proceedings, Balwois, Ohrid, Macedonia. Retreived from: http://balwois.org

Vélez-Espino, L. A., \& Koops, M. A. (2009). Recovery potential assessment for lake sturgeon in Canadian designatable units. North American Journal of Fisheries Management, 29(4), 1065-1090.

Veríssimo, D., MacMillan, D. C. \& Smith, R. J. (2011). Toward a systematic approach for identifying conservation flagships. Conservation Letters, 4, 1-8. 
Ward, D. L. (ed) (1998). Effects of mitigative measures on productivity of white sturgeon populations in the Columbia River downstream from McNary Dam, and determine the status and habitat requirements of white sturgeon populations in the Columbia and Snake Rivers upstream from McNary Dam. Annual Progress Report (April 1997-March 1998). Portland, OR: Boneville Power Administration.

Webb, M. A. H. (2003). Investigation of potential methods by which to determine and monitor reproductive senescence in white sturgeon. Oregon State University.

Welsh, A., Hill, T., Quinlan, H., Robinson, C., \& May, B. (2008). Genetic assessment of lake sturgeon population structure in the Laurentian Great Lakes. North American Journal of Fisheries Management, 28(2), 572-591.

Williot, P., Arlati, G., Chebanov, M., Gulyas, T., Kasimov, R., Kirschbaum, F., Patriche, N., Pavlovskaya, L. P., Poliakova, L., Pourkazemi, M., Kim, Y., Zhuang, P., \& Zholdasova, I. M. (2002). Status and management of Eurasian sturgeon: an overview. International Review of Hydrobiology, 87(5-6), 483-506.

Williot, P., Brun, R., Rouault, T., Pelard, M., Mercier, D., \& Ludwig, A. (2005). Artificial spawning in cultured sterlet sturgeon, Acipenser ruthenus L., with special emphasis on hermaphrodites. Aquaculture, 246(1), 263-273. 


\section{Figure captions}

Fig. 1. Structure of the respondents regarding their fields of research. Bars represent proportions of respondents within each of the three continental regions. Multiple answers were permitted.

Fig. 2. Responses regarding the presence of senescence in sturgeons and paddlefish $(\mathrm{N}=265)$, and its importance in undisturbed populations $(\mathrm{N}=224)$.

Fig. 3. Responses regarding the common mating type in sturgeons and paddlefish (N $=257$ ), within each of the three continental regions.

Fig. 4. Responses regarding the homing fidelity strength in sturgeons and paddlefish $(\mathrm{N}=252)$ and the major homing drivers $(\mathrm{N}=186)$.

Fig. 5. Proportion of the respondents supporting reports of extreme longevities observed in different species as realistic $(\mathrm{N}=249)$, presented both for species experts and other respondents: beluga (Huso huso) - 118 years (Billard and Lecointre, 2001), European sturgeon (Acipenser sturio) - 100 years or more (Jarić and Gessner, 2013), Atlantic sturgeon (A. oxyrinchus) - more than 100 years (inferred based on the age at maturity in northern populations; Jarić and Gačić, 
2012), white sturgeon (A. transmontanus) - 104 years (Rien and Beamesderfer, 1994), lake sturgeon (A. fulvescens) - 154 years (Haxton et al., 2016).

Fig. 6. Proportion of the respondents supporting reports of maximum body length and weight observed in different species as realistic $(\mathrm{N}=244)$, presented both for species experts and other respondents: beluga (Huso huso) - $600 \mathrm{~cm}$ (Holčik, 1989), up to $900 \mathrm{~cm}$ (Rochard et al., 1991), $1500 \mathrm{~kg}$ (Rochard et al., 1991), $3000 \mathrm{~kg}$ (Holčik, 1989), kaluga (H. dauricus) - 600 cm (Krykhtin and Svirskii, 1997), 1000 $\mathrm{kg}$ (Chen, 2007), European sturgeon (Acipenser sturio) - $600 \mathrm{~cm}$ (Jarić and Gessner, 2013), $1000 \mathrm{~kg}$ (Schoenevelde, 1624), Atlantic sturgeon (A. oxyrinchus) - $500 \mathrm{~cm}$ (Hilton et al., 2016), white sturgeon (A. transmontanus) - $600 \mathrm{~cm}$ (Billard and Lecointre, 2001), $800 \mathrm{~kg}$ (Billard and Lecointre, 2001).

Fig. 7. Responses regarding the probable intrinsic population growth rate in sturgeons and paddlefish in general $(\mathrm{N}=241)$, presented separately for the general respondent sample, group of experienced researchers and those working on population ecology and modelling.

Fig. 8. Proportion of the respondents supporting potential of sturgeons to be used within different surrogate species concepts $(\mathrm{N}=239)$, presented separately for the general respondent sample, group of researchers working in the field of ecology and those working on policy and management issues. 
Fig. 9. Ranking of the five major anthropogenic impacts upon population status based on their relevance $(\mathrm{N}=239)$, within each of the three continental regions $(0$ least relevant, 4 - most relevant).

Fig. 10. Scoring of different international conventions regarding their effectiveness and positive impact on protection, restoration and sustainable management of sturgeon populations $(\mathrm{N}=231)$. Upper figure - grading scores for each convention; lower figure - proportion of respondents, within each of the three continental regions, who stated that they were not sure about the proper grading. CITES Convention on International Trade in Endangered Species of Wild Fauna and Flora, Bonn - Convention on the Conservation of Migratory Species of Wild Animals, Bern - Bern Convention on the Conservation of European Wildlife and Natural Habitats, OSPAR - Convention for the Protection of the Marine Environment of the NorthEast Atlantic, CBD - Convention on Biological Diversity, UNCLOS - United Nations Convention on the Law of the Sea, Ramsar - Convention on Wetlands.

Fig. 11. Uncertainty of respondents towards different questions, as indicated in the questionnaire. 

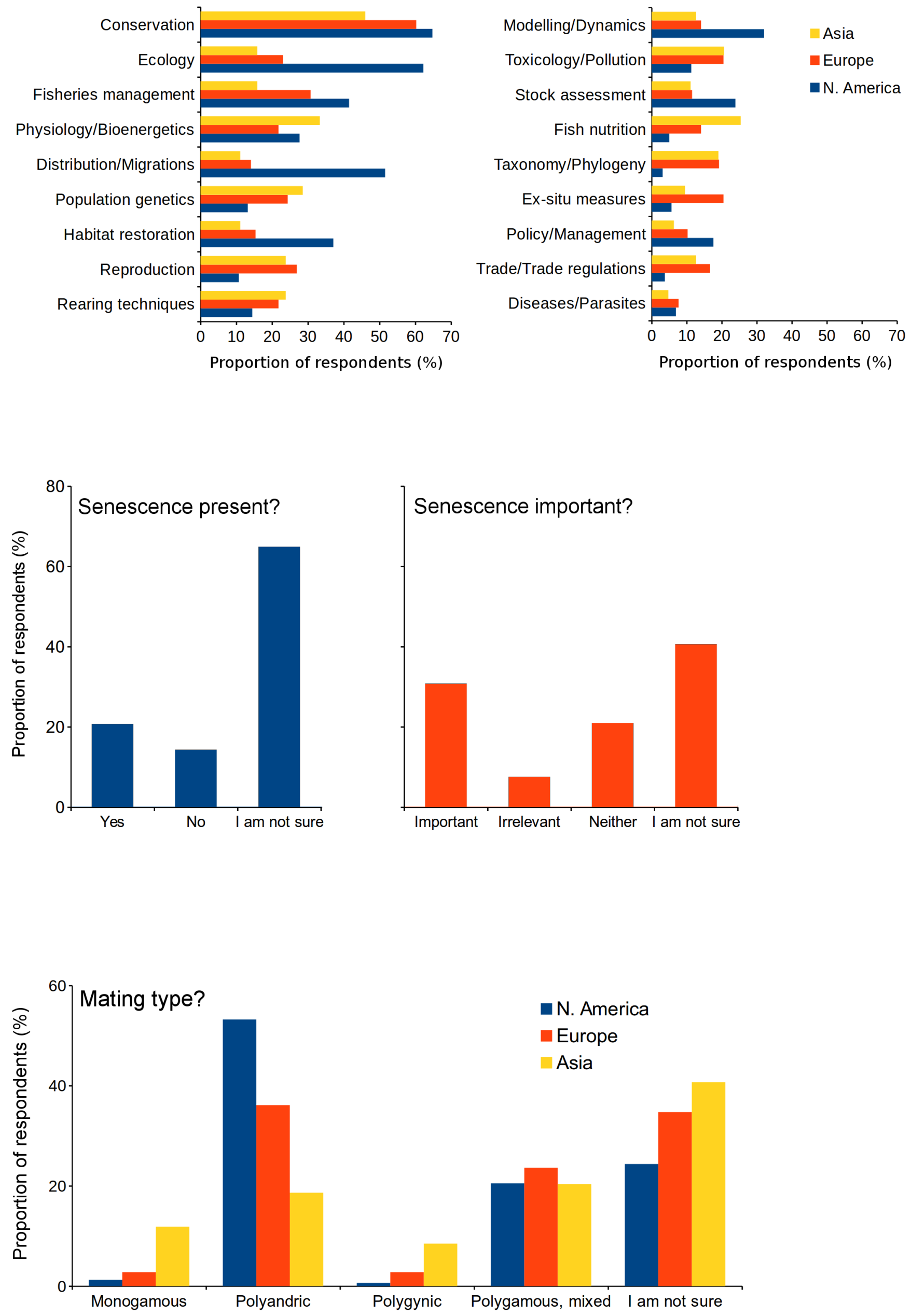

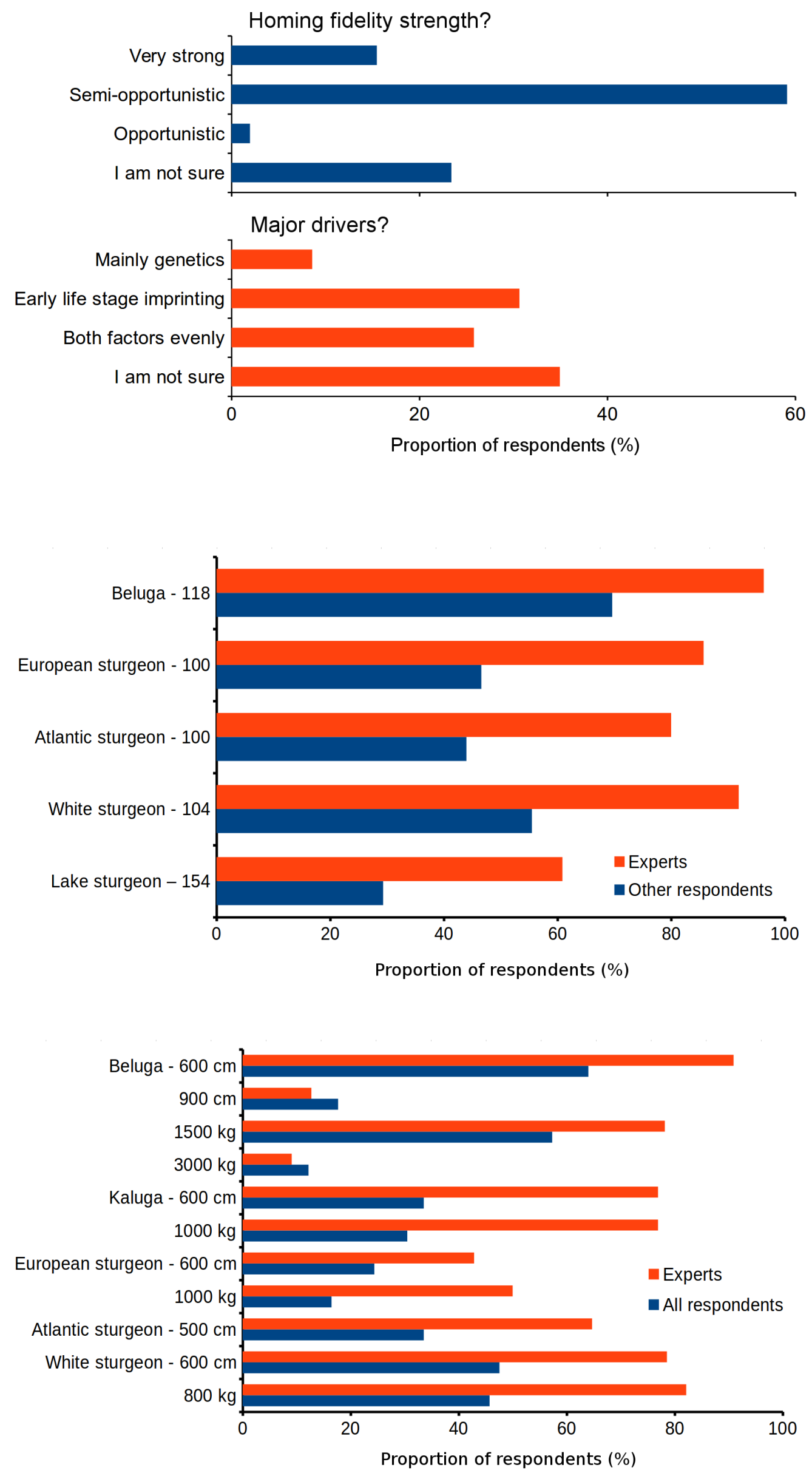

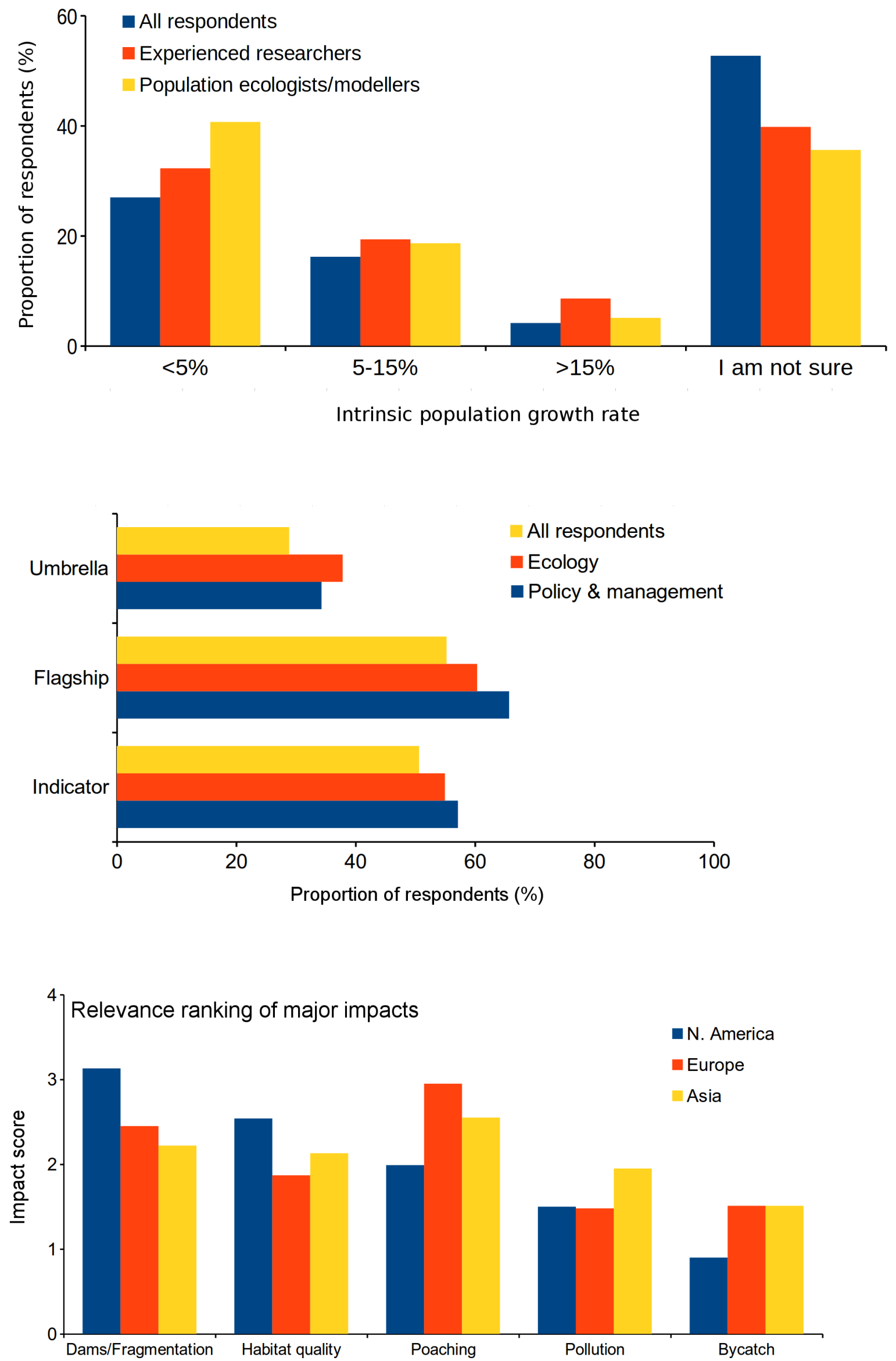

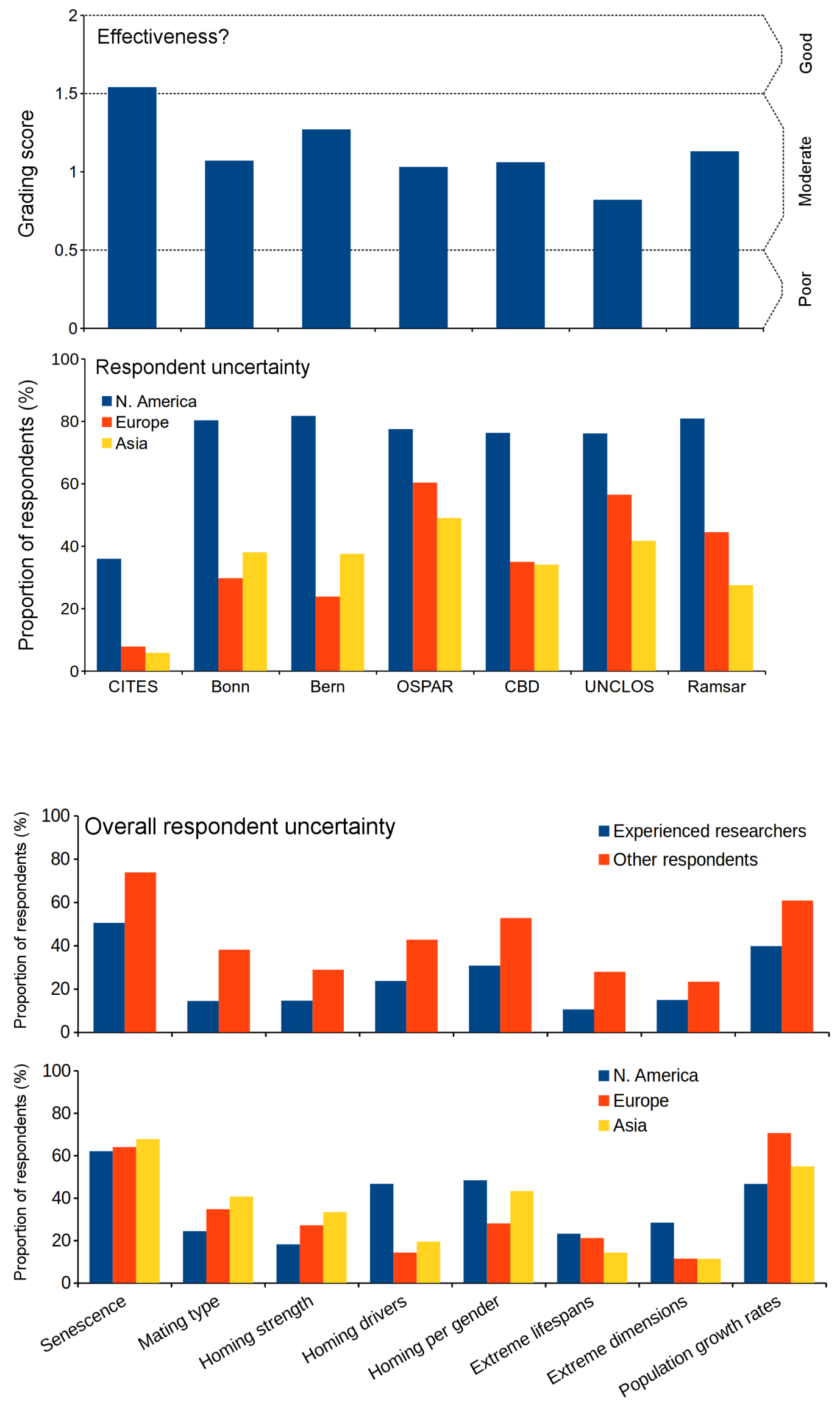